\title{
Análise espacial dos conflitos da arborização urbana da Cidade de Rio Tinto - PB
}

\author{
Spatial analysis of the conflicts of urban treatment of the City of Rio Tinto - PB \\ Análisis espacial de conflictos de arborización urbana de la Ciudad de Rio Tinto - PB
}

Recebido: 01/04/2021 | Revisado: 11/04/2021 | Aceito: 15/04/2021 | Publicado: 29/04/2021

\author{
Fabrício Ferreira Jerônimo \\ ORCID: https://orcid.org/0000-0003-3458-1248 \\ Universidade Federal da Paraíba, Brasil \\ E-mail: fabricio.jf102@gmail.com \\ Sofia Erika Moreira Gomes \\ ORCID: https://orcid.org/0000-0001-8091-7457 \\ Universidade Federal da Paraíba, Brasil \\ E-mail: sofiaerika@gmail.com \\ Zelma Glebya Maciel Quirino \\ ORCID: https://orcid.org/0000-0003-0396-107X \\ Universidade Federal da Paraíba, Brasil \\ E-mail: zelmaglebya@gmail.com \\ Maria Alinny Cruz da Silva \\ ORCID: https://orcid.org/0000-0002-2846-1883 \\ Universidade Federal Rural de Pernambuco, Brasil \\ E-mail: mariaalinny.cruz@gmail.com \\ Josefa Rodrigues Carneiro \\ ORCID: https://orcid.org/0000 0003-4269-0452 \\ Universidade Federal de Pernambuco, Brasil \\ E-mail: josefa2carneiro@gmail.com
}

\begin{abstract}
Resumo
A urbanização faz com que a ocupação das cidades ocorra de forma desordenada, representando significativas mudanças físicas da natureza, e a arborização constitui uma ferramenta para minimizar tais impactos urbanos. Para analisar a arborização é indispensável o uso de dados geográficos obtidos através de medições topográficas, técnicas de sensoriamento remoto, receptores de GPS, etc. Através das técnicas de geoprocessamento é possível mapear situações diversas tais como, problemas fitossanitários, conflitos com redes de eletricidade, sinalização, ou quaisquer tipos de caracteres, os quais assumem papel fundamental para o manejo da arborização. Este trabalho consistiu em registrar os conflitos da arborização da cidade de Rio Tinto - PB e mapeá-los com as técnicas de Geoprocessamento. O estudo foi realizado de novembro de 2016 a julho de 2018. As variáveis analisadas foram: localização, entorno, interferências, dimensões, equilíbrio, ações e mapeamento. Um total de 931 indivíduos foram catalogados. De modo geral, as árvores encontram-se dentro dos padrões recomendados no que se refere à fiação elétrica, equilíbrio do caule e da copa e dimensões, necessitando de algumas ações de manejo. As ações recomendadas para um melhor aproveitamento dos serviços proporcionados pelas árvores precisam ser decididas com base em um planejamento prévio. Com a expansão da cidade, novas formas de intervenções serão necessárias futuramente, visando minimizar os impactos.
\end{abstract}

Palavras-chave: Vegetação urbana; Infraestrutura urbana; Manejo urbano; Geoprocessamento.

\begin{abstract}
Urbanization causes the occupation of cities to occur in a disorderly manner, representing significant physical changes in nature, and afforestation is a tool to minimize such urban impacts. To analyze afforestation, it is essential to use geographic data obtained through topographic measurements, remote sensing techniques, GPS receivers, etc. Through geoprocessing techniques it is possible to map different situations such as phytosanitary problems, conflicts with electricity networks, signaling, or any type of characters, which assumes a fundamental role in the management of afforestation. This work consisted of registering the conflicts of the afforestation of the city of Rio Tinto - PB and mapping them with the techniques of Geoprocessing. The study was carried out from November 2016 to July 2018. variables analyzed were: location, surroundings, interferences, dimensions, balance, actions and mapping. A total of 931 individuals were cataloged. . In general, the trees are within the recommended standards with regard to electrical wiring, stem and crown balance and dimensions, requiring some management actions. The recommended actions for a better use of the services provided by the trees need to be decided based on prior planning. With the expansion of the city, new forms of interventions will be needed in the future, in order to minimize the impacts.
\end{abstract}

Keywords: City vegetation; Urban infrastructure; Urban management; Geoprocessing. 


\begin{abstract}
Resumen
La urbanización hace que la ocupación de las ciudades ocurra de manera desordenada, lo que representa cambios físicos significativos en la naturaleza, y la forestación es una herramienta para minimizar dichos impactos urbanos. Para analizar la forestación es fundamental utilizar datos geográficos obtenidos a través de mediciones topográficas, técnicas de teledetección, receptores GPS, etc. Mediante técnicas de geoprocesamiento es posible mapear diferentes situaciones como problemas fitosanitarios, conflictos con las redes eléctricas, señalización, o cualquier tipo de caracteres, lo que asume un papel fundamental en el manejo de la forestación. Este trabajo consistió en registrar los conflictos de forestación de la ciudad de Rio Tinto - PB y mapearlos con las técnicas de Geoprocesamiento. El estudio se realizó de noviembre de 2016 a julio de 2018. Las variables analizadas fueron: ubicación, entorno, interferencias, dimensiones, equilibrio, acciones y mapeo. Se catalogaron un total de 931 individuos. En general, los árboles se encuentran dentro de los estándares recomendados en cuanto a cableado eléctrico, equilibrio y dimensiones de tallos y copas, requiriendo algunas acciones de manejo. Las acciones recomendadas para un mejor uso de los servicios que brindan los árboles deben decidirse en base a una planificación previa. Con la expansión de la ciudad, se necesitarán nuevas formas de intervenciones en el futuro, con el fin de minimizar los impactos.
\end{abstract}

Palabras clave: Vegetación urbana; Infraestructura urbana; Gestión urbana; Geoprocesamiento.

\title{
1. Introdução
}

Nos últimos anos, o intenso processo de urbanização fez com que a ocupação das cidades ocorresse de forma desordenada, representando os pontos mais significativos de mudanças físicas da natureza pela ação antrópica (Comune \& Suriani-Affonso, 2014; Gomes et al., 2016), modificando totalmente a cobertura vegetal original em sua área por necessidades de infraestrutura (Periotto et al., 2016).

Com a cidade de Rio Tinto, no Estado da Paraíba, não foi diferente, a mesma foi construída em decorrência da instalação da fábrica têxtil "CIA de Tecidos Rio Tinto" criada pelo grupo Lundgren, que desencadeou o crescimento da malha urbana para suportar as necessidades da população (Coreia, 2001). Sua fundação começou quando os irmãos Lundgren compraram as terras do "Engenho Preguiça" e em 1918 começaram as alterações ambientais com os desmatamentos, drenagem do solo, a plantação de dezenas de eucaliptos e aterros de manguezais em torno dos quais a cidade cresceu. Devido à instalação da fábrica, Rio Tinto nasceu urbana, onde o censo de 1950 a indicava como a terceira maior cidade da Paraíba (Panet, 2002). Portanto, a implantação da indústria têxtil foi o fator determinante no processo de crescimento populacional e degradação ambiental.

A arborização urbana é utilizada nos centros das cidades como uma estratégia para tentar minimizar os impactos ambientais causados pelo crescimento urbano (Albertin et al., 2011; Santos et al., 2012). Portanto, é necessário incluir a vegetação como um fator indispensável no planejamento urbano para tentar tornar esse ambiente o mais próximo possível do ambiente natural (Albertin et al., 2011), visto que o processo de degradação é crescente e irreversível.

Nas cidades onde há planejamento da arborização de forma correta, tem-se uma preocupação de tornar o ambiente urbano diversificado, trazendo conforto direto ou indireto às pessoas e evitar danos aos elementos urbanos e ao meio ambiente (Romani et al., 2012; Silva et al., 2016). Porém, para analisar a arborização é indispensável o uso de dados geográficos obtidos através de medições topográficas, técnicas de sensoriamento remoto, receptores de GPS, etc. (Oliveira Filho \& Silva, 2010). Segundo Fonseca et al. (2014) e Silva et al. (2016), a utilização do Sistema de Informações Geográficas (SIGs) representa uma oportunidade para análise ambiental urbana integrada que direcionam o planejamento urbano e orientam a implantação da arborização urbana de forma consistente. Através das técnicas de geoprocessamento é possível mapear situações diversas tais como, problemas fitossanitários, conflitos com redes de eletricidade, sinalização, ou quaisquer tipos de caracteres, os quais assumem papel fundamental para o manejo da arborização (Fonseca et al., 2014).

Portanto, levando em consideração a importância da realização de inventários para estudo da arborização urbana, e a sua utilização para a geração de bancos de dados que poderão ser usados na gestão de áreas verdes urbanas, o objetivo deste trabalho consiste em registrar os conflitos da arborização da cidade de Rio Tinto - PB, e mapeá-los com as técnicas de Geoprocessamento. 


\section{Metodologia}

\subsection{Caracterização da área de estudo}

O estudo foi realizado no perímetro urbano do município de Rio Tinto, situado na microrregião do Litoral Norte e mesorregião da Zona da Mata, Estado da Paraíba (Figura 1). Está inserido entre as coordenadas $06^{\circ} 48^{\prime} 10^{\prime}$ ' S e 3504' 51" W, distando cerca de $53 \mathrm{~km}$ da capital, João Pessoa. Possui uma extensão territorial de $466 \mathrm{~km}^{2}$ e população estimada de 24.000 habitantes (IBGE, 2018). Limita-se com os municípios de Mamanguape, Marcação, Baía da Traição, Mataraca, Lucena e Santa Rita.

O clima desta região é denominado de Am (tropical e chuvoso) com temperaturas médias que oscilam entre $24^{\circ} \mathrm{C}$ a $27^{\circ} \mathrm{C}$ e variações pluviométricas entre 1800 a $2000 \mathrm{~mm} / \mathrm{ano}$, segundo a classificação de Koppen, atualizada por Alvares et al. (2013). Apresenta sazonalidade bem definida, com verão entre os meses de novembro a abril, e período chuvoso de maio a outubro.

Figura 1. Mapa de localização da área estudada no município de Rio Tinto - PB.

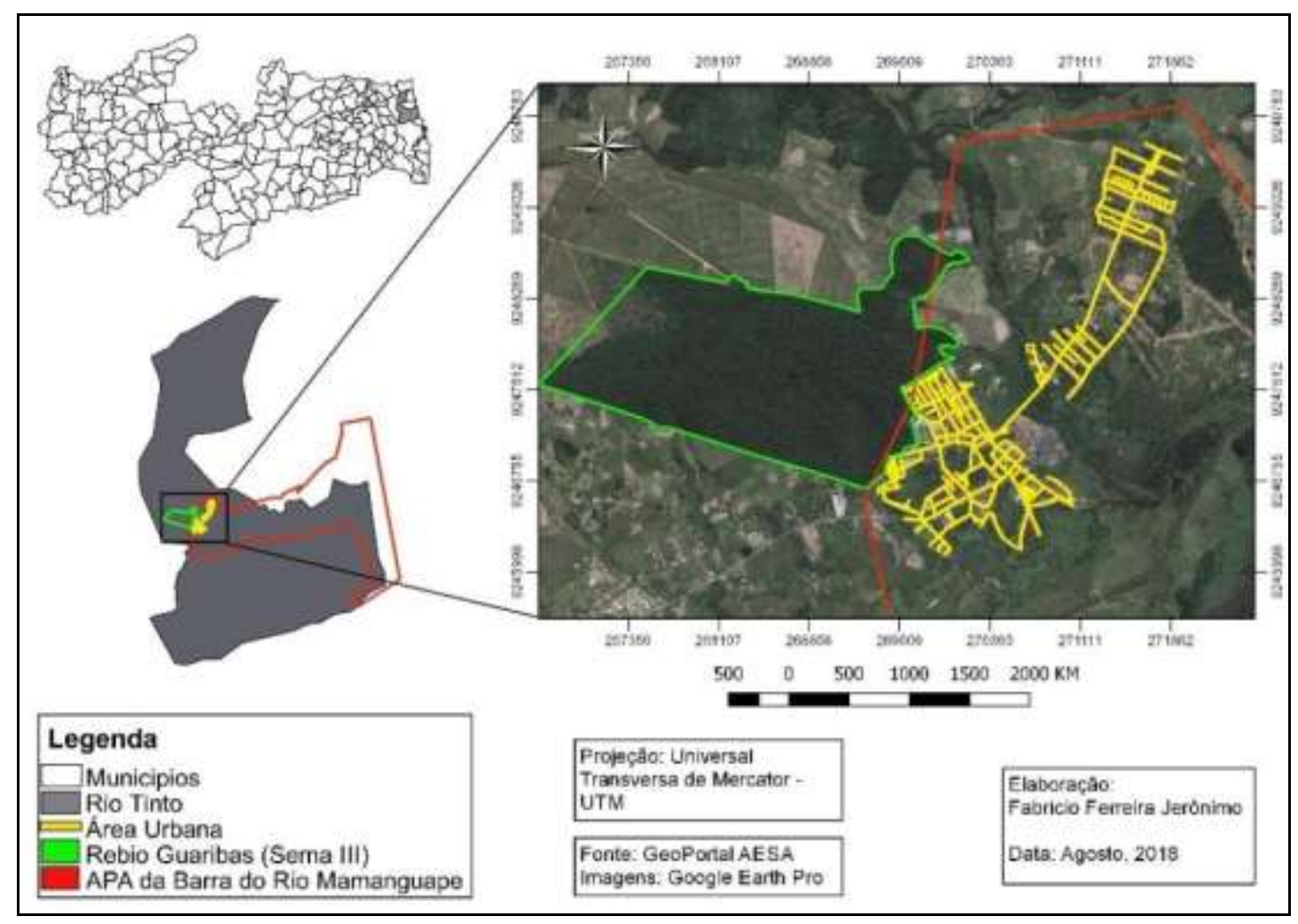

Fonte: Autores.

\subsection{Coleta de Dados}

As variáveis analisadas em campo foram efetuadas com o auxílio de uma planilha de levantamento de dados, de acordo com Silva Filho et al.(2002) e Lacerda et al. (2011), adaptada para as condições locais.

Os dados foram coletados através do inventário arbóreo quali-quantitativo de acordo com (Bortoleto et al., 2007; Coletto et al,. 2008; Miranda et al, 2015; Silva et al., 2016) no qual foi realizado o levantamento de todos os indivíduos arbóreos presentes na cidade. A coleta de dados foi realizada no período de novembro de 2016 a julho de 2018. As informações foram parametrizadas da seguinte forma:

I - Localização, entorno e interferência das árvores: 
Localização geral: Canteiros centrais, calçadas ou vias públicas.

Localização relativa: Localização da árvore em relação aos elementos urbanos, junto à parede (quando se encontrava em calçadas), junto à divisa (quando se encontrava próximo ao meio fio) e centrada.

Contato com outras árvores: Quando as árvores estavam com as copas interligadas.

Contato com fiação, postes, iluminação, sinalização, muro/construção: Foram considerados como contato (quando a árvore tocava os elementos urbanos), potencial (quando o indivíduo, pelo seu crescimento normal, vai entrar em contato com os elementos urbanos), ausente (quando não existia possibilidade de contato).

Afloramento da raiz: Foi observado quais os problemas causados pelas raízes, como quebra de canteiros, calçadas, calçamentos, bancos, etc.

Estado do colo: Foi registrado o tipo de cobertura na base da árvore (solo, grama, ervas, pavimento, cimento, metralha ou brita).

II - Dimensões e equilíbrio:

Altura geral: Foi realizada através do aplicativo telemóvel Smart Measure (versão 1.6) (Brito Neto et al., 2016) e de estimativas visuais (Freitas et al., 2016). De acordo com seu tamanho, as árvores foram consideradas: de pequeno porte aquelas que atingiram até 4,0 $\mathrm{m}$ de altura; médio porte - acima de 4,0 a 8,0 $\mathrm{m}$ e de grande porte - as maiores que 8,0 $\mathrm{m}$.

Equilíbrio do caule: Foi analisado se estava reto, inclinado ou torto.

Equilíbrio da copa: Foi avaliado se a copa estava equilibrada (mesma proporção de copa para ambos os lados da árvore) ou desequilibrada (maior quantidade de ramos de um lado da árvore, favorecendo a queda do indivíduo).

III - Ações executadas e recomendadas - Foram observadas quais atividades tinham sido realizadas nas árvores pelos órgãos municipais ou pela população, tais como: Poda de conformação, poda de limpeza, poda de segurança, poda drástica, topiaria, poda da grama, limpeza do canteiro, plantio, reparo de danos, controle de pragas, substituição e ampliação de canteiro. Em seguida foram definidas que ações, conforme o diagnóstico geral da árvore, são necessárias para a manutenção, adequação ou recuperação do bom estado dos indivíduos.

IV- Mapeamento e localização espacial - Foram coletadas as coordenadas geográficas das árvores com a utilização do aplicativo telemóvel GPS Status. Posteriormente, as coordenadas foram verificadas no programa Google Earth Pro para conferir se a localização obtida pelo aplicativo estava de acordo com a imagem do satélite. Para a confecção dos mapas, foi utilizado o software QGIS versão 2.18.

\section{Resultados e Discussão}

\subsection{Dimensões e Equilíbrio}

\subsubsection{Altura Geral}

Nesse estudo foram catalogados um total de 931 indivíduos arbóreos (ver Jerônimo et al., 2019). A arborização de Rio Tinto - PB pode ser considerada de médio porte, com a maioria dos indivíduos com alturas variando de 4 a 8 metros (Figura 2). Os indivíduos que foram considerados de pequeno porte com altura total até $4 \mathrm{~m}$, obtiveram um total de 232 (24,9\%). Os de grande porte correspondem a um total de 120 indivíduos $(12,8 \%)$, todos com altura acima de $8 \mathrm{~m}$. Verificou-se que em algumas espécies de médio e grande porte foram realizadas podas drásticas, devido aos conflitos com a fiação elétrica, de maneira a prejudicar os exemplares (Figura 6). O porte dos exemplares é de grande importância para a adequação dos indivíduos dentro dos espaços urbanos, portanto, a escolha correta das espécies é essencial. Sendo assim, quanto maior o porte do exemplar plantado, melhores serão as condições térmicas proporcionadas, porém será maior as chances de interferência com as fiações elétricas (Oliveira et al., 2016) e outros elementos urbanos. 
Neste estudo, observou-se que havia árvores em contato com a fiação elétrica (Figura 6). Este conflito pode estar relacionado ao porte e ao tamanho da copa, mas sobretudo à falta de manejo adequado, o que pode acarretar sérios danos aos moradores da cidade. Cabe ressaltar que a arborização que desenvolve altura superior a $5 \mathrm{~m}$ alcança a rede de serviços aérea e está sujeita às podas realizadas pelas concessionárias, processo que deforma os vegetais e em muitas situações, compromete sua integridade e desenvolvimento (Salvi et al., 2011). Periotto et al. (2016); Damo, Hefler e Jacobi (2015) e Oliveira et al. (2015) ressaltam que esses conflitos podem ser minimizados com a gestão adequada destas árvores, através de ações como: podas de redução de porte com critérios técnicos e através da escolha de mudas adequadas no momento dos plantios, evitando assim, prejuízos à saúde das plantas e às características arquitetônicas de suas copas.

Figura 2. Classe de alturas (A), Classes de altura da primeira ramificação (B), Percentual do equilíbrio da copa (C), Percentual do equilíbrio do caule (D) dos indivíduos inventariados na arborização da cidade de Rio Tinto - PB.
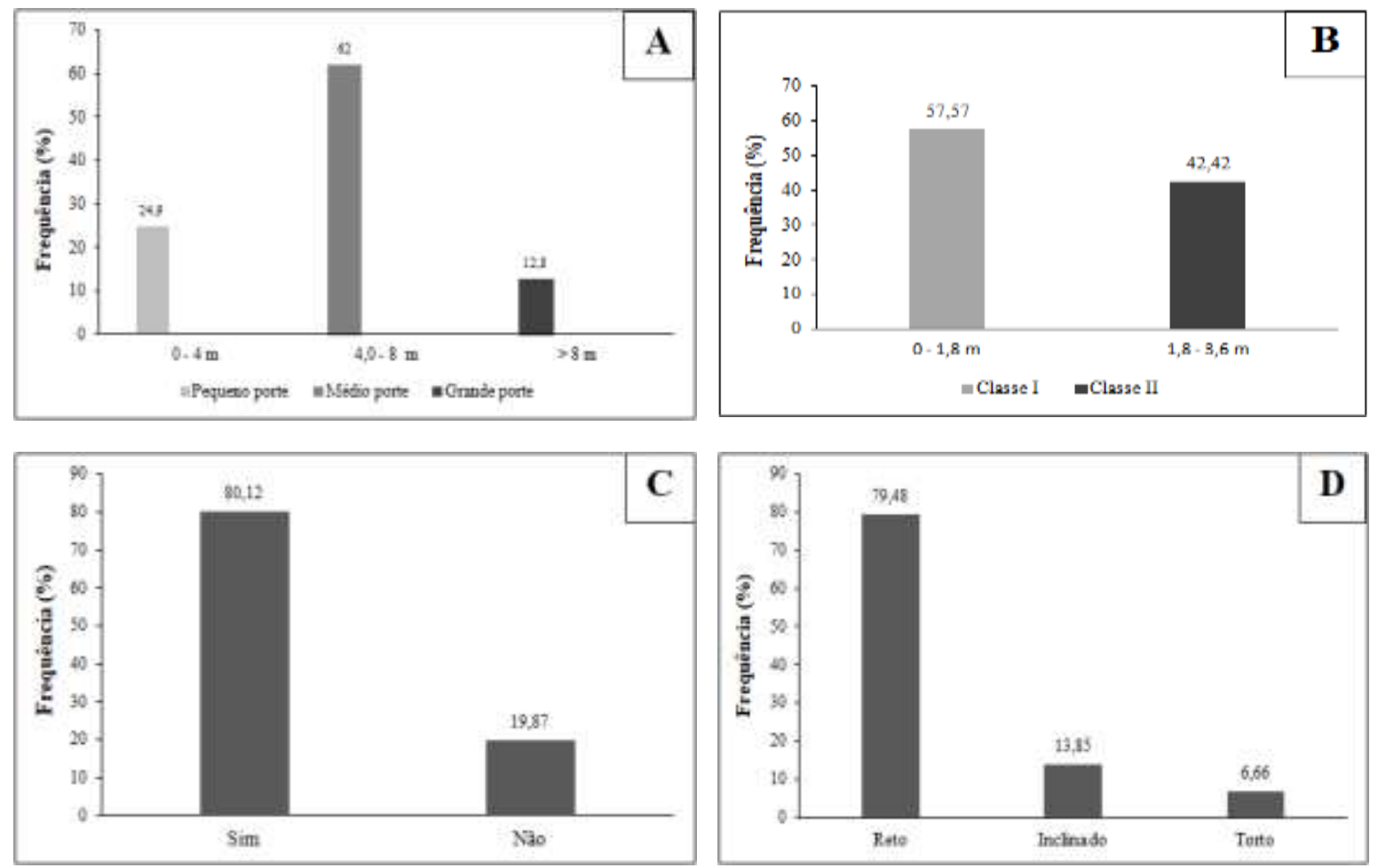

Fonte: Autores.

\subsubsection{Altura da primeira ramificação}

Observa-se que 536 indivíduos $(57,57 \%)$ utilizados na arborização da cidade estão com a primeira ramificação abaixo de 1,8m (Figura 2 - B). Este é um dado que confirma a falta de condução e o plantio das espécies inventariadas. Deve-se considerar a importância da altura mínima da ramificação das árvores, principalmente quando essas são plantadas em calçadas, visando reduzir possíveis acidentes e dificultando a passagem de pessoas que circulam na área. De acordo com Lima Neto et al. (2010), espécies localizadas em calçadas com a altura da primeira ramificação abaixo de 2,0 m tornam-se um problema aos pedestres. Porém, os indivíduos se encontram na cidade de Rio Tinto, na maioria dos casos estão fora da área de circulação, portanto sem causar problemas aos pedestres ou veículos. 


\subsubsection{Equilíbrio do caule e da copa}

No censo realizado observou-se que $746(80,1 \%)$ indivíduos estavam com suas copas equilibradas (Figura 2 - C). Em relação ao equilíbrio do caule, verificou-se que 739 (79,3\%) estavam retos, $129(13,8 \%)$ inclinados e $62(6,65 \%)$ tortos (Figura 2 - D). O equilíbrio geral da árvore é o que vai definir a boa distribuição do volume do caule e da copa e juntos constituem um pré-requisito para a segurança na arborização. A falta de equilíbrio das árvores pode ser provocada por vários fatores, como por exemplo, podas mal executadas, crescimento irregular do vegetal, estresse. No período de coleta, pôde-se constatar que a maior parte da arborização da cidade está em boas qualidades em relação ao equilíbrio do caule e da copa, porém podemos encontrar alguns indivíduos que estavam com riscos de queda, podendo causar sérios riscos aos moradores e edificações da cidade.

\subsection{Entorno e Interferências}

\subsubsection{Localização Geral e Relativa}

Foi observado que 557 árvores estão localizadas nos canteiros centrais; 230 nas calçadas e 144 nas vias públicas (Figura 3 - A). A maioria das árvores 741 estavam centradas nos canteiros, 157 estavam próximas à divisa (meio fio) e 33 próximas às paredes das edificações (Figura 3 - B).

No estudo da localização relativa das árvores de Rio Tinto - PB é importante observar que a cidade apresenta um bom posicionamento dos exemplares arbóreos, estando a maioria em alameda no centro das ruas. Em se tratando de ruas estreitas (Média = 9,57 metros), o ideal é que os indivíduos arbóreos estejam centralizados para que possam sombrear os dois lados da rua e ter um mínimo contato com as edificações e demais estruturas públicas. Sendo assim, de acordo com Gomes e Lamberts, (2009) a vegetação absorve a radiação solar excessiva e proporciona sombreamento, atua no resfriamento e na umidificação do ar, contribuindo, em ambas as vias, para o estabelecimento de microclimas mais agradáveis. 
Figura 3. Localização geral (A), Localização relativa (B) Afloramento das raízes (C) e Tipos de pavimentos (D) dos indivíduos arbóreos inventariados da cidade de Rio Tinto - PB.
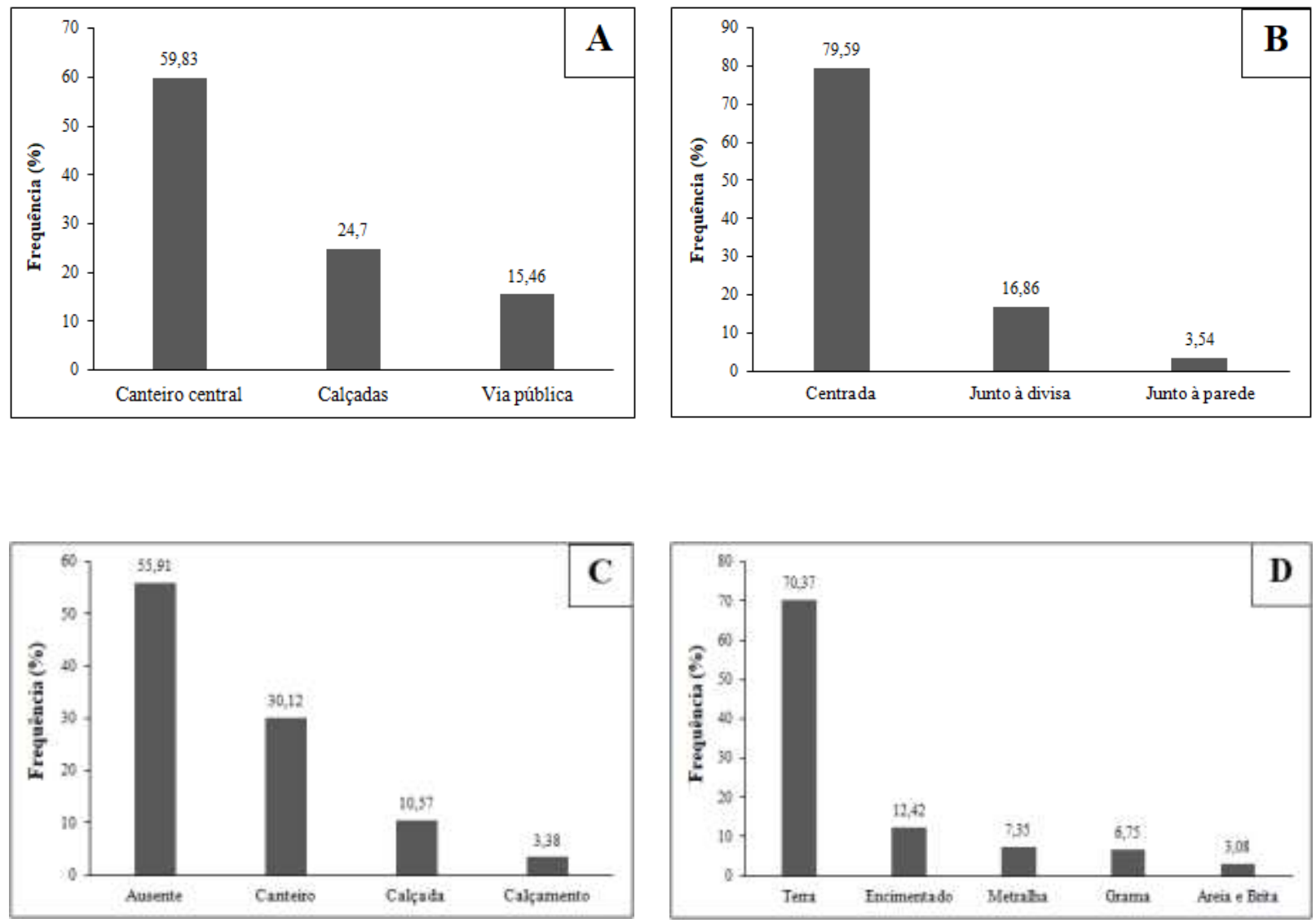

Fonte: Autores.

\subsubsection{Afloramento das raízes}

$\mathrm{Na}$ análise sobre afloramento das raízes (Figura 3 - C) constatou-se que a maior ocorrência foi registrada em canteiros $285(30,12 \%)$, seguida de calçadas $100(10,57 \%)$, causando danos. Pode-se observar na (Figura 4) a distribuição espacial dos indivíduos com esse problema.

Este problema está relacionado principalmente a falhas na infraestrutura que levam à falta de oxigenação das raízes, por estarem submersas em solos compactados ou completamente obstruídos por concreto ou outros tipos de materiais. Sufocadas, as raízes tendem a crescer mais próximas à superfície (Figura 6 - C). O fluxo de pedestres e veículos fica comprometido com estes afloramentos. Outro fator a ser considerado é a própria morfologia das raízes de algumas espécies, que por crescerem naturalmente acima do solo, são inadequadas para arborização de ruas, mas podem ser usadas em praças públicas, desde que haja espaço para o seu crescimento.

A quebra de canteiros, calçadas e pavimentos, provocadas pelo afloramento das raízes é um problema comum nas cidades brasileiras (Santos et al., 2015; Periotto et al., 2016; Damo, Hefler e Jacobi, 2015). Gonçalves e Meneguetti, (2015) relatam que na cidade de Maringá é comum o estrangulamento das árvores causado pela pavimentação das calçadas, situação que chega a acontecer muito próximo ao tronco delas.

A soma dos percentuais de quebra de calçadas e canteiros na cidade de Rio Tinto foi observada em quase metade (40,69\%) das árvores analisadas. As espécies Ficus benjamina L. e Terminalia. catappa L. foram as que causaram os maiores danos. Resultados semelhantes foram catalogados por Souza e Cintra (2007) e Santos et al. (2015), onde F. benjamina e T. 
catappa também são citadas como espécies que apresentaram conflitos com a quebra de calçadas. Periotto et al. (2016) e Damo et al. (2015) ressaltam que o $F$. benjamina e outras espécies arbóreas têm potencial para gerar problemas, principalmente com calçadas e demais pavimentações. Portanto, tais espécies devem ser evitadas em futuros plantios.

A maneira mais eficaz de evitar danos em pavimentações ocasionados por raízes de uma árvore é a adequação de um espaço para o seu desenvolvimento, de forma que as infraestruturas urbanas não sejam afetadas. Um bom exemplo de estrutura que comporta várias árvores em alameda são as calçadas verdes. Pela sua organização e estrutura, elas permitem que as águas das chuvas penetrem no solo, atenuam os riscos de alagamentos nas ruas, auxiliando no sequestro de carbono e permitem que as raízes das árvores se desenvolvam com mais espaço, diminuindo assim os conflitos ocasionados nos canteiros e calçadas, além de fornecerem uma boa estética ao local (Gengo \& Henkes, 2013). Em Rio Tinto pode-se observar a existência de calçadas verdes, porém as palmeiras imperiais foram plantadas fora do espaço destinado às árvores, além disso, elas só comportam árvores de pequeno porte em virtude da presença de fiação elétrica (Figura 6 - D).

\subsubsection{Tipo de pavimento}

O tipo de pavimento predominante no colo das árvores (área de drenagem) foi a cobertura de terra, presente em 70,37\% indivíduos avaliados, seguida de árvores com o colo pavimentado com cimento (12,42\%) (Figura 3 - D). 
Figura 4. Distribuição espacial dos indivíduos arbóreos com afloramento das raízes na cidade de Rio Tinto - PB.

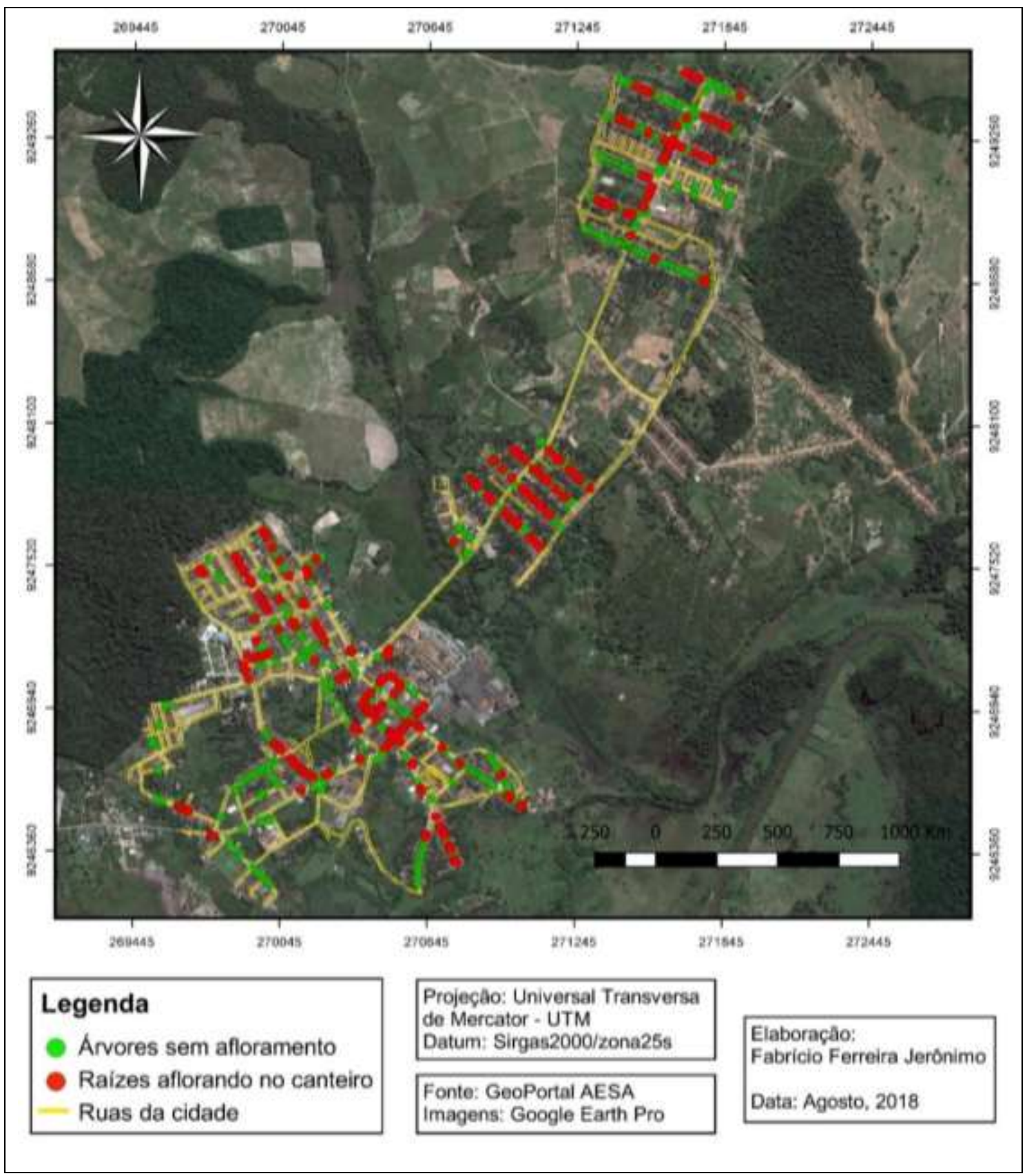

Fonte: Autores.

\subsubsection{Contato com a fiação}

Da população arbórea inventariada, a maior parte dos indivíduos 657 (70,6\%) não teve nenhum conflito com a fiação elétrica. Entretanto, 274 (29,4\%) estavam em conflito, podendo causar riscos de choque elétrico ou danos à fiação. Pode-se observar na (Figura - 5) a distribuição espacial dos indivíduos que se encontravam com esse problema. Entre as espécies catalogadas, S. siamea e $F$. benjamina foram responsáveis pela maior parte dos conflitos com a fiação na área de estudo. 
Figura 5. Distribuição espacial dos indivíduos arbóreos em contato com a fiação elétrica na arborização de Rio Tinto - PB.

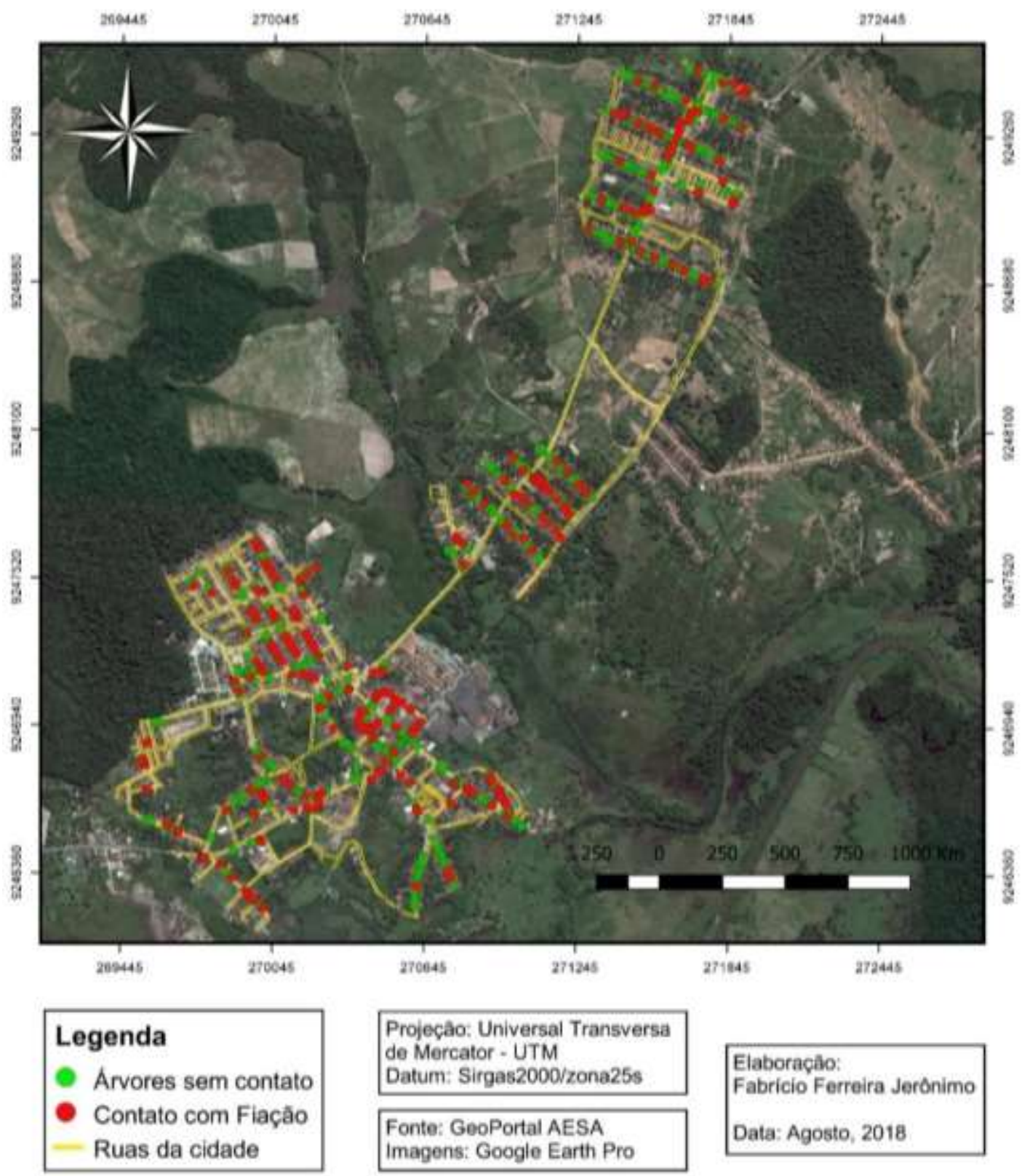

Fonte: Autores.

\subsubsection{Postes e Iluminação}

Em relação ao posteamento, observou-se que a maior parte dos indivíduos 826 (88,7\%) não apresentou nenhum conflito, 64 (6,87\%) deles estavam em contato. Quanto à iluminação pública, constatou-se que 48 indivíduos (5,15\%) estavam em contato com a iluminação. Quanto aos problemas relacionados com a sinalização do tráfego de veículos, não foi diagnosticado nenhum conflito. 
Figura 6. Exemplos de indivíduos da arborização urbana da cidade de Rio Tinto - PB:(A) Poda drástica realizada em $T$. catappa; (B) Indivíduo da espécie S. siamea em contato com a fiação; (C) Calçada verde na Rua da Mangueira sem nenhum indivíduo arbóreo.

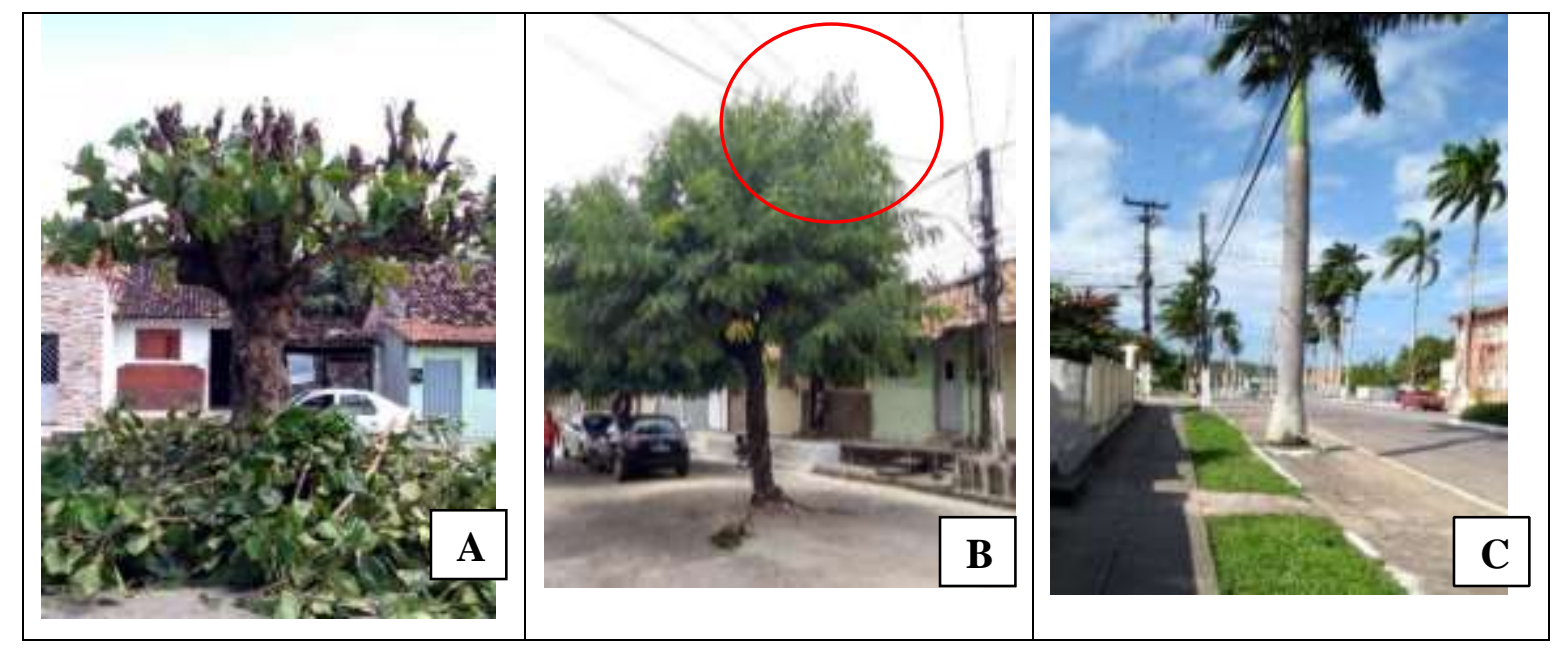

Fonte: Autores.

\subsection{Ações executadas e recomendadas}

\subsubsection{Ações executadas}

Em relação às ações executadas, verificou-se que 63,26\% das árvores não apresentaram nenhum tipo de manejo adequado. Porém, observa-se em número insuficiente a existência de algumas ações como: podas drásticas, podas de condução e topiaria, visto que muitas das árvores poderiam ser mais bem conduzidas para que pudessem desenvolver com melhores condições fitossanitárias e com o mínimo de conflitos com o seu entorno. Em apenas 28,57\% das árvores foram observadas podas de conformação. Foi registrado também ações como podas severas (5,04\%).

Foram observadas durante a pesquisa ações pontuais da concessionária de energia elétrica e funcionários da prefeitura sobre as árvores. Foram observadas algumas falhas quanto ao uso de equipamentos de segurança individual e coletiva, uso de ferramentas inadequadas e danos aos vegetais.

\subsubsection{Ações recomendadas}

Detectou-se que 499 (32,42\%) árvores necessitam de podas de conformação, sendo essa ação necessária para evitar que elas entrem em conflito com a fiação elétrica. Apesar da remoção das árvores ser uma das alternativas geralmente indicadas para sanar problemas com a fiação, não se recomenda a retirada de nenhuma árvore na cidade de Rio Tinto, apenas a troca do atual modelo de fiação convencional pelo modelo compacto, onde as chances de interferência são menores. A cidade também necessita do monitoramento periódico das árvores, especialmente em épocas de chuva, quando os acidentes são mais frequentes.

Verificou-se que 28,72\% precisam de ações para o controle das pragas. 265 (17,22\%) necessitam de ampliação dos canteiros, para que seja ampliada a área de infiltração de água e oxigênio nas raízes. 9,94\% das árvores necessitam de limpeza do canteiro, para que se diminua a incidência de poluentes no solo. 110 (7,15\%) necessitam de poda de limpeza, para a retirada de galhos mortos ou em processo de apodrecimento. 53 árvores $(3,44 \%)$ precisam ser substituídas por oferecem sérios riscos de queda (Figura 7).

Nos futuros plantios da cidade de Rio Tinto, deve-se evitar o uso de F. benjamina e T. catappa, por serem as espécies que menos se adaptaram às condições urbanas. Faz-se necessário o melhor conhecimento sobre as espécies arbóreas adaptadas 
às condições urbanas, através dos exemplos observados em outras cidades e lembrando que a substituição deve ser feita de forma gradativa, de preferência com espécies nativas.

Figura 7. Percentual de indivíduos os quais necessitam de ações na arborização da cidade de Rio Tinto - PB.

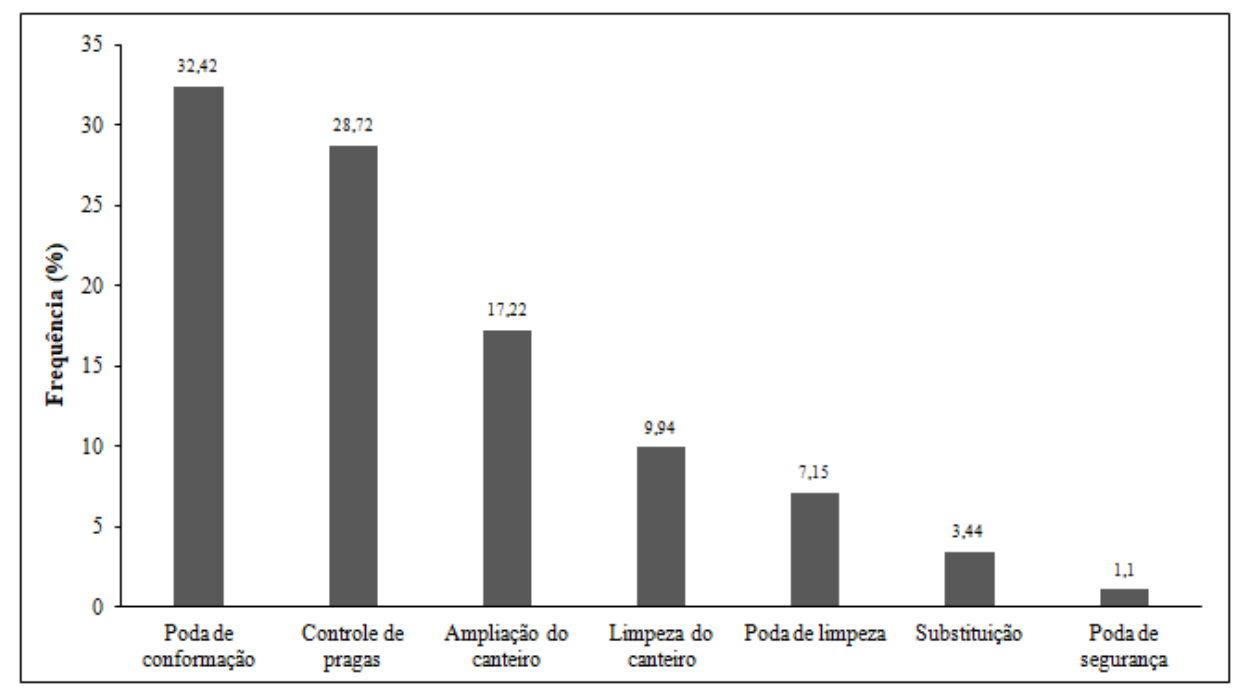

Fonte: Autores.

\section{Conclusão}

De modo geral conclui-se que a arborização da cidade de Rio Tinto - PB está bem adaptada com relação aos seus equipamentos urbanos. Porém carece da intervenção direta e dos órgãos de governo municipais, para receber os cuidados necessários. Dessa forma, como não há essas intervenções da forma correta, as ações de manejo ocorrem de maneira aleatória e sem planejamento, ficando os cuidados desses vegetais sem um direcionamento técnico adequado. Como a cidade ainda é de pequeno porte, os problemas parecem controláveis, porém ela se encontra em rápido crescimento urbano, e isso pode representar novos desafios para gestão municipal no que se refere não só ao manejo da arborização, como também de outras áreas verdes urbanas.

Espera-se que essas informações possam ser ponto de partida para o desenvolvimento de novos trabalhos na arborização da cidade, e que visem pesquisas voltadas a informações sobre as espécies que são empregadas no ambiente urbano, focando no tipo de desenvolvimento das árvores, como por exemplo: avaliando o porte e qual o tipo de crescimento das raízes dos indivíduos, selecionando as espécies que poderão ser utilizadas futuramente na arborização da cidade de Rio Tinto-PB.

\section{Referências}

Albertin, R. M., Angelis, R., Neto, G. A. \& Angelis, B. L. D. (2011). Diagnóstico quali-quantitativo da arborização viária de Nova Esperança, Paraná, Brasil. Revista da Sociedade Brasileira de Arborização Urbana, 6(3), 128-148. http://dx.doi.org/10.5380/revsbau.v6i3.66477

Alvares, C. A., Stape, J. L., Sentalhas, P. C., Moraes, G., Leonardo, J. \& Sparovek, G. (2013). Köppen'climate classification map for Brazil. Meteorologische Zeitschrift. 22(6), 711-728. http://doi.org/10.1127/0941-2948/2013/0507

ABNT, Associação Brasileira de Normas Técnicas. (2015). Acessibilidade a edificações, mobiliário, espaços e equipamentos urbanos. NBR 9050, Rio de Janeiro.

Bortoleto, S., Silva Filho, D. F., Souza, V. C., Ferreira, M. A. P. F., Polizel, J. L. \& Ribeiro, R. C. S. (2007). Composição e distribuição da arborização viária da Estância de Águas de São Pedro-SP. Revista da Sociedade Brasileira de Arborização Urbana. 2(3). http://dx.doi.org/10.5380/revsbau.v2i3.66327

Brito Neto, R. L., Barreto, P. A. B. \& Prado, W. B. (2016). Utilização de aplicativo telemóvel para medição da altura total das árvores. IV Semana De Engenharia Florestal Da Bahia E I Mostra De Pós-Graduação Em Ciências Florestais Da UESB. Anais. 
Coreia, T. B. (2001). De Vila Operária a Cidade-Companhia: As aglomerações criadas por empresas no vocabulário especializado e vernacular. Revista Brasileira de Estudos Urbanos e Regionais n.4. http://dx.doi.org/10.22296/2317-1529.2001n4p83

Coletto, E. P., Muller, N. G. \& Wolski, S. S. (2008). Diagnóstico da Arborização das vias públicas do município de Sete de Setembro RS. Revista da Sociedade Brasileira de Arborização Urbana, 3(2), 110-122. 10.5380/REVSBAU.V3I2.66353

Comune, M. D. \& Suriani-Affonso, A. L. (2014). Análise de três áreas verdes urbanas em Guarapuava, Paraná. Ambiência - Revista do Setor de Ciências Agrárias e Ambientais. 10(3). 10.5935/ambiencia.2014.03.06

Damo, A., Hefler, S. M. \& Jacobi, U. S. (2015). Diagnóstico da arborização em vias públicas dos bairros Cidade Nova e Centro na cidade de Rio Grande - RS. Revista da Sociedade Brasileira de Arborização Urbana, 10(1), 43-60. http://dx.doi.org/10.5380/revsbau.v10i1.63246

Fonseca, S. F., Santos, D. C. \& Trindade, W. M. (2014). Técnicas de geoprocessamento aplicadas na classificação e avaliação da distribuição das espécies arbóreas nas praças de Buritizeiro/MG. Geografia Ensino \& Pesquisa, 18(20. 10.5902/2236499412503

Freitas, A. F., Santos, J. S. \& Lima. R. B. (2016). Diagnóstico quantitativo e qualitativo da arborização do espaço intra-urbano da UFPB campus I. Gaia Scientia. 10(4), 236-251.http://dx.doi.org/10.21707/gs.v10.n04a19

Gengo, R. C. \& Henkes, J. A. (2013). A utilização do paisagismo como ferramenta na preservação e melhoria ambiental em área urbana. R. Gest. Sust. Ambient., Florianópolis, 1(2), 55 - 81.http://dx.doi.org/10.19177/rgsa.v1e2201255-81

Gomes, P. S. \& Lamberts, R. (2009). O estudo do clima urbano e a legislação urbanística: considerações a partir do caso Montes Claros, MG. Ambiente Construído, 9(1), 73-91.

Gomes, E. M. C., Rodrigues, D. M. S., Santos, J. T. \& Barbosa, E. J.(2016). Análise quali-quantitativa da arborização de uma praça urbana no Norte do Brasil. Nativa, 4(3), 179-186. 10.31413/nativa.v4i3.3180

Gonçalves, A. \& Meneguetti, K. (2015). Projeto de arborização como patrimônio da cidade. Ambiente Construído, 15(1), 99-118.

Instituto Brasileiro de Geografia e Estatística - IBGE, (2018).

Jerônimo, F. F., Gomes, S. E. M. \& Quirino, Z. G. M. (2019) Inventário das árvores urbanas da cidade de Rio Tinto/PB. Revista Ibero Americana de Ciências Ambientais, 10(1), 1-9, 2019. http://doi.org/10.6008/CBPC2179-6858.2019.001.0001

Lacerda, R. M. A., Lira Filho, J. A. \& Santos, R. V. (2011). Indicação de espécies de porte arbóreo para a arborização urbana no semiárido paraibano. Revista da Sociedade Brasileira de Arborização Urbana, 6(1), 51-68. http://dx.doi.org/10.5380/revsbau.v6i1.66579

Lima Neto, E. M., Biondi, D. \& Araki, H. (2010). Aplicação do SIG na arborização viária - unidade amostral em Curitiba, PR. In: Simpósio Brasileiro De Ciências Geodésicas E Tecnologias Da Geoinformação, 3, 2010, Recife. Anais. p. 01 - 06.

Miranda, Y. C., Machado, M. S., Silva, L. S., Estevam, R., Martins Neto, F. F. \& Caxambu, M. G. (2015). Análise quali-quantitativa da Arborização de ruas do município de Godoy Moreira PR. Revista da Sociedade Brasileira de Arborização Urbana, 10(1), 71 81.http://dx.doi.org/10.5380/revsbau.v10i1.63210

Oliveira, A. F., Pereira, J. A. A., Pereira, G. A., Coelho, S. J., Neves, C. L. P., Rezende, S. W. \& Garcia, F. H. S. (2015). Modalidades de poda avaliadas na arborização viária sob rede elétrica no Estado de Minas Gerais. Revista da Sociedade Brasileira de Arborização Urbana, 10(2), 1-13. http://dx.doi.org/10.5380/revsbau.v10i2.63100

Oliveira, A. F., Pereira, G. A., Santos, E., Oliveira, K. D. S., Pompermayer, R. S., Coelho, S. J. \& Pereira, J. A. A. (2016). Arborização viária conflituosa com a rede elétrica na região oeste de Belo Horizonte -MG. Revista da Sociedade Brasileira de Arborização Urbana, 11(2), 27-44. http://dx.doi.org/10.5380/revsbau.v11i2.63415

Oliveira Filho, P. C. \& Silva, S. V. K. (2010). Um sistema de informações para suporte espacial e de decisões à gestão da arborização urbana no município de Guarapuava, Paraná. Revista da Sociedade Brasileira de Arborização Urbana, 5(3), 82-96. http://dx.doi.org/10.5380/revsbau.v5i3.66305

Panet, A. (2002). Rio Tinto -Estrutura urbana, trabalho e cotidiano. Editora Unipê.

Periotto, F., Pituco, M. M., Helmann, A. C., Santos, T. O. \& Bortolotti, S. L. (2016). Analysis of urban afforestation in Medianeira, Paraná. Revista da Sociedade Brasileira de Arborização Urbana, 11(2), 59-74.

Romani, G. N., Gimenes, R., Silva, M. T., Pivetta, K. F. L. \& Batista, G. S. (2012). Análise quali-quantitativa da arborização na Praça XV de Novembro em Ribeirão Preto - SP, Brasil. Revista Árvore, 36(3), 479-487.

Salvi, L. T., Hardt, L. P. A., Rovedder, C. E. \& Fontana, C. S. (2011). Trees along streets - green tunnels - in Porto Alegre, RS, Brazil: quantitative and qualitative evaluation. Revista Árvore, 35(2). https://doi.org/10.1590/S0100-67622011000200008.

Santos, C. Z. A. Ferreira, R. A., Santos, L. R., Santos, L. I., Gomes, S. H. \& Graça, D. A. S. (2015). Análise qualitativa da arborização urbana de 25 vias públicas da cidade de Aracaju - SE. Ciência Florestal, 25(3), 751-763. https://doi.org/10.5902/1980509819678.

Santos, T. O. B., Lisboa, C. M. C. A. \& Carvalho, F. G. (2012) Análise da arborização viária do bairro de Petrópolis, Natal, RN: (2012). Uma Abordagem para diagnóstico e planejamento da flora urbana, Revista da Sociedade Brasileira de Arborização Urbana, 7(4), 90-106. http://dx.doi.org/10.5380/revsbau.v7i4.66546

Silva Filho, D. F., Pizetta, P. U. C., Almeida, J. B. S. A. de, Pivetta, K. F. L.\& Ferraudo, A. S. (2002). Banco de dados relacional para cadastro, avaliação e manejo da arborização em vias públicas. Revista Árvore, 26(5), 629 - 642. https://doi.org/10.1590/S0100-67622002000500014 
Research, Society and Development, v. 10, n. 5, e9310514571, 2021

(CC BY 4.0) | ISSN 2525-3409 | DOI: http://dx.doi.org/10.33448/rsd-v10i5.14571

Silva, K. A. R., Leles, P. S. S., Giácomo, R. G. \& Mendonça, B. A. F. (2016). Diagnóstico e uso de Geoprocessamento para manejo da Arborização Urbana do Bairro Centro da Cidade do Rio de Janeiro - RJ. Revista da Sociedade Brasileira de Arborização Urbana, 11(4), 98-114. http://dx.doi.org/10.5380/revsbau.v11i4.63461

Souza, R. C. \& Cintra, D. P. (2007). Arborização viária e conflitos com equipamentos urbanos no bairro da Taquara, RJ. Revista e Ambiente. 14(1), 25 - 33. 